\title{
Growth and study of barium oxalate single crystals in agar gel
}

\author{
P V DALAL* and K B SARAF \\ PG Department of Physics, Pratap College, Amalner 425 401, India
}

MS received 15 December 2005; revised 22 May 2006

\begin{abstract}
Barium oxalate was grown in agar gel at ambient temperature. The effect of various parameters like gel concentration, gel setting time and concentration of the reactants on the growth of these crystals was studied. Prismatic platy shaped spherulites and dendrites were obtained. The grown crystals were characterized by $\mathrm{X}$-ray powder diffractometry, infrared spectroscopy, thermogravimetric and differential thermal analysis. An attempt is made to explain the spherulitic growth mechanism.
\end{abstract}

Keywords. Barium oxalate; agar gel; XRD; IR; TGA/DTA.

\section{Introduction}

Crystal growth is a heterogeneous chemical process in which conversion from one phase to another phase of a compound is involved. In the field of crystal growth, gel technique has become more popular and has been used by several investigators (Joshi and Trivedi 1970; Ittyachen and Kurien 1979; Joshi et al 1981). Due to its simplicity (Armington and O'Cornnar 1968; Ranadive et al 1969), it can be successfully used at room temperature to suppress nucleation centres (Arora 1981) and is suitable for crystals having low solubility (Dennis and Henisch 1967).

The ferroelectric and ferroelastic properties of rare earth oxalates and molybdates have wide applications in electro and acousto optical devices (Barkley et al 1971, 1972; Sapriel and Vacher 1977). Synthesis of superconducting compounds by the controlled precipitation of oxalates followed by calcinations has been reported (Caillaud et al 1988).

Oxalate crystals are insoluble in water and they decompose before the melting point (Prasad et al 1996). Synthesis of rare earth oxalates has been carried out using the gel method (Jayakumari et al 1995; Sushma Bhat et al 1995; Raju et al 1998). Transition metal oxalates were also grown by this method (Arora and Tony Abraham 1981). Barium copper oxalate crystal was grown in silica hydrogel (Bangera and Mohan Rao 1992) and barium oxalate crystal was grown by precipitation of alkaline earth metal oxalate powders from its aqueous solution (Pactor 1977). The work on barium oxalate is reported only in silica hydrogel. Hence the purpose of the present paper is to report the growth and influence of various parameters on the growth mechanism of single crystals of barium oxalate in agar gel at ambient temperature.

\footnotetext{
*Author for correspondence (yash_paresh@yahoo.co.in)
}

\section{Experimental}

The growth of barium oxalate crystal was carried out in agar gel. All chemicals such as acetic acid, barium chloride, oxalic acid and agar-agar were of AR grade.

In the present work, agar-agar gel (Brezina and Harvankova 1991; Agrawal et al 1999) was preferentially used for the growth of crystals by single and double diffusion techniques.

A test tube having $25 \mathrm{~cm}$ in length and $2.5 \mathrm{~cm}$ in diameter was employed. In single diffusion, hot aqueous agar gel and oxalic acid solution were thoroughly mixed and kept in the test tube for setting. After setting and aging, the gel, barium chloride, was added to the above gel.

Now on reversing the reactants, in single diffusion, hot aqueous agar gel and barium chloride solutions were thoroughly mixed and kept in the test tube for setting. After setting and aging the gel, oxalic acid, was added.

In double diffusion, the $\mathrm{U}$ tube was filled up to proper heights with hot agar-agar solution and kept for setting and aging. Oxalic acid solution was poured into one limb and barium chloride solution was poured into the other limb of the U tube.

The reaction, which leads to the growth of crystals, was expressed as

$$
\mathrm{BaCl}_{2}+\mathrm{H}_{2} \mathrm{C}_{2} \mathrm{O}_{4}=\mathrm{BaC}_{2} \mathrm{O}_{4}+2 \mathrm{HCl}
$$

\section{Results and discussion}

The optimum conditions for growing crystals are given in table 1.

In single diffusion, after a few days, dendritic and spherulitic growths were observed. The dendritic growth of barium oxalate is as shown in figure 1, while figure 2 shows prismatic platy shaped transparent crystals at the 
Table 1. Optimum conditions for growth of barium oxalate crystals.

\begin{tabular}{lcc}
\hline Conditions & Single diffusion & Double diffusion \\
\hline$\%$ of gel & $1 \cdot 5$ & 1.5 \\
Concentration of barium chloride & $1 \mathrm{M}$ & $1 \mathrm{M}$ \\
Concentration of oxalic acid & $1 \mathrm{M}$ & $1 \mathrm{M}$ \\
Gel setting period & 6 days & 12 days \\
Gel aging & $48 \mathrm{~h}$ & $48 \mathrm{~h}$ \\
Period of growth & 80 days & 60 days \\
Temperature & Room temp. & Room temp. \\
Quality & Transparent, opaque & Opaque \\
Size & $17 \times 4 \times 2,4 \times 3 \times 2$ and 4 mm diameter & 4 mm diameter \\
\hline
\end{tabular}

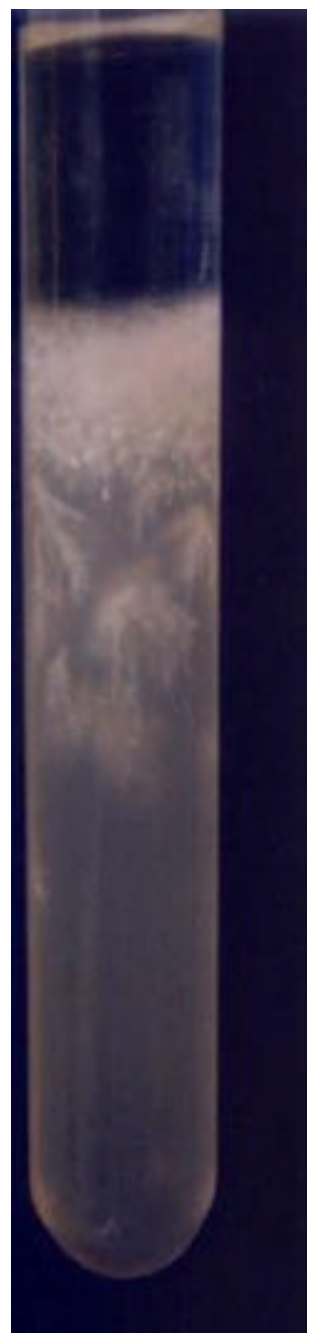

Figure 1. Dendritic growth of barium oxalate.

interstitial and spherulitic growth well inside the gel on reversing the reactant in single diffusion. In double diffusion, spherulitic growth was observed as shown in figure 3. Figure 4 shows some good quality transparent as well as spherulite crystals.

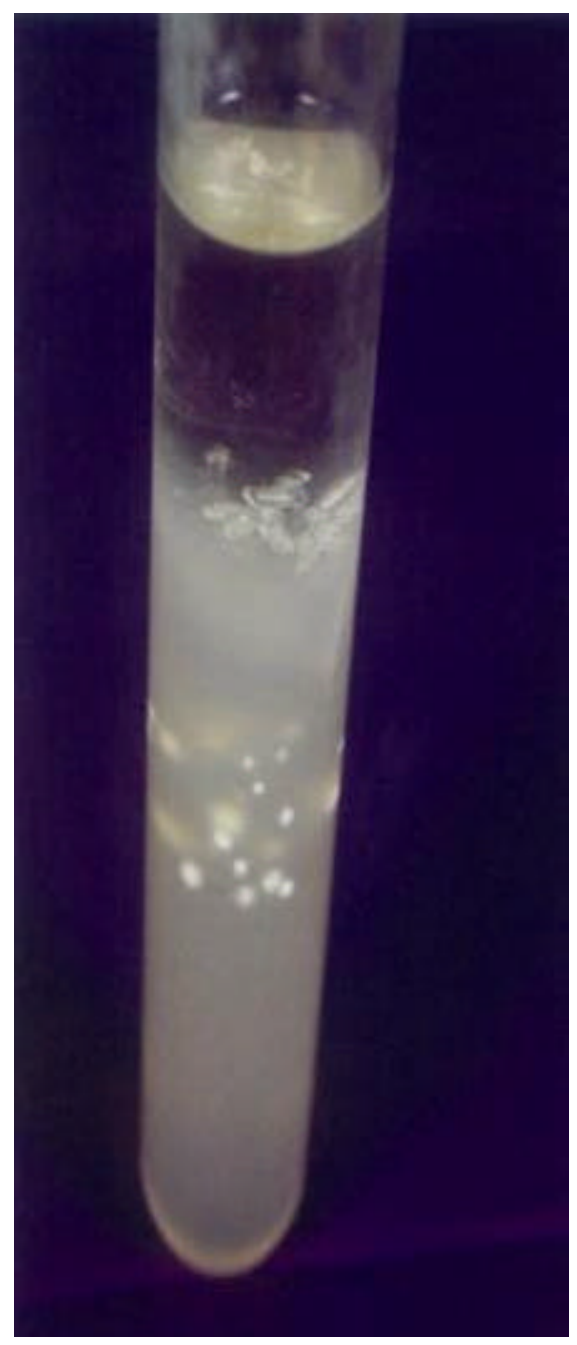

Figure 2. Prismatic platy shaped transparent crystals at the interstitial and spherulites inside the gel.

Different parameters such as concentration of reactants, $\mathrm{pH}$ of gel, impurities in the solvent, gel setting time etc have considerable effect on growth rate. In the steady state of concentration gradient, growth rate also becomes steady which favours growth of spherulite crystals. However, 


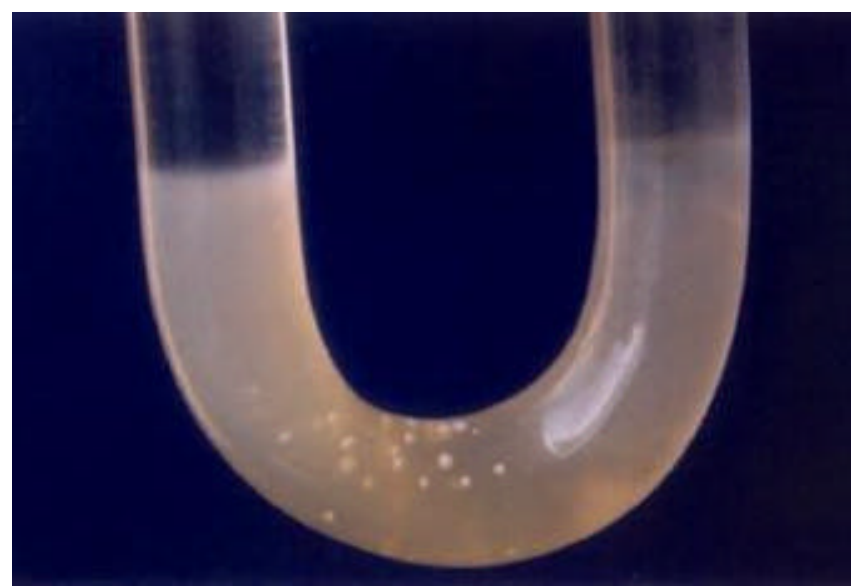

Figure 3. Spherulite crystals of barium oxalate in U-tube.

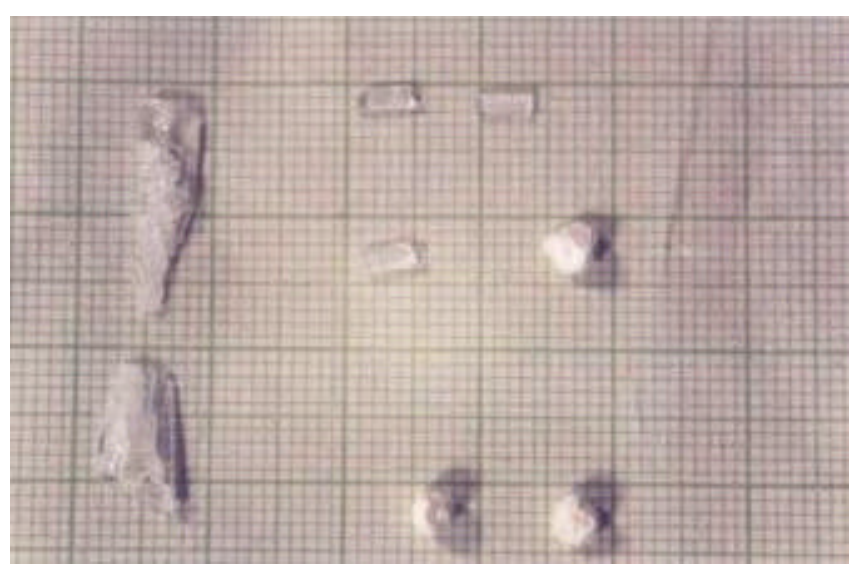

Figure 4. Some good quality transparent as well as spherulite crystals.

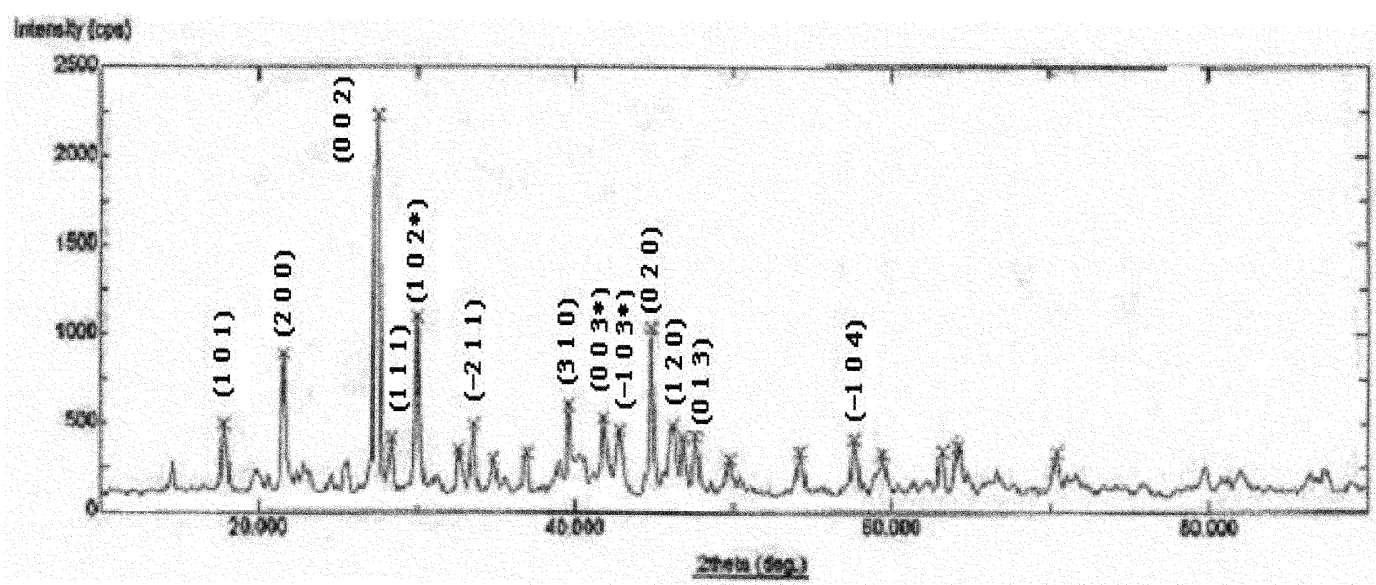

Figure 5. X-ray diffractogram of barium oxalate.

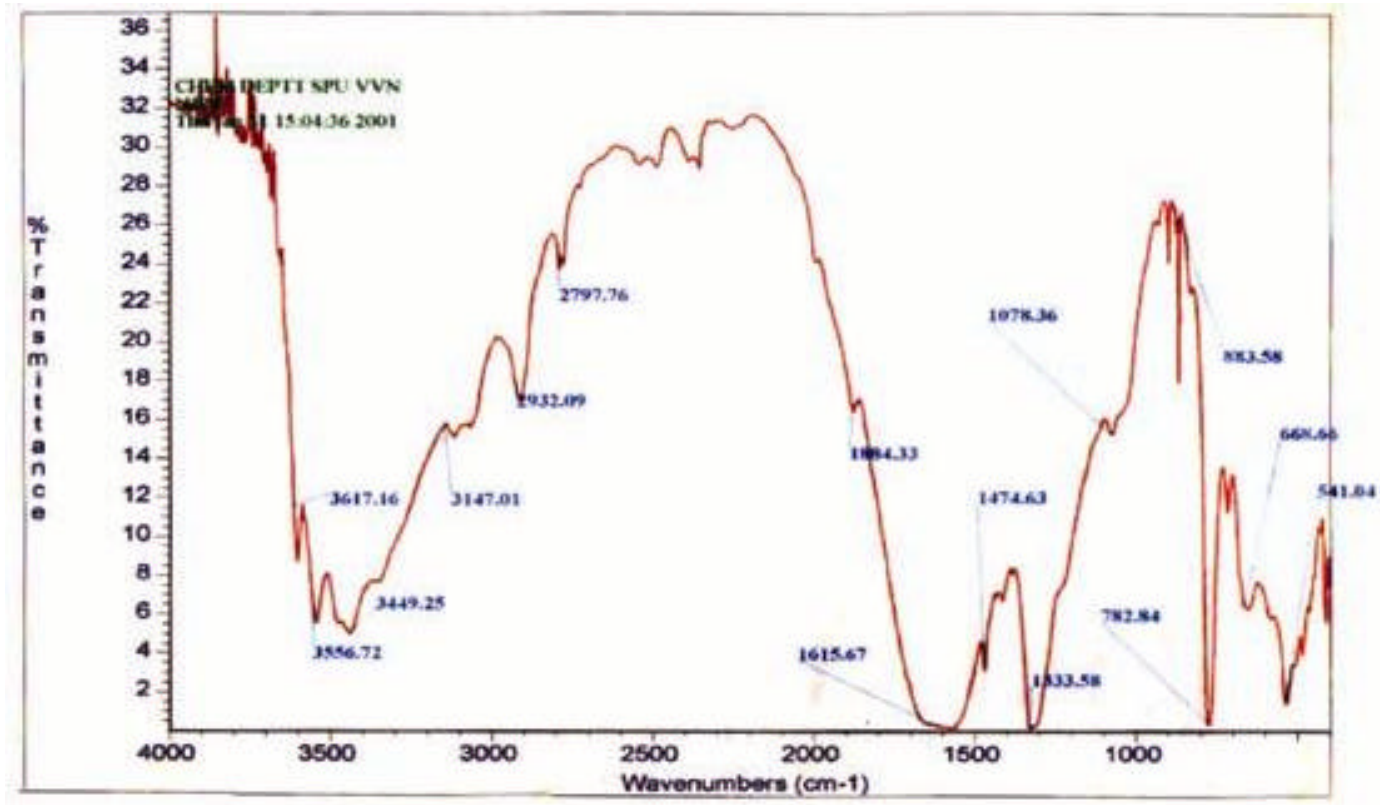

Figure 6. Infrared spectra (IR) of barium oxalate. 
very slow rate of growth along one direction results in the platy crystals. Fast growth rate in one particular direction leads to the formation of elongated crystals like dendrite crystals.

\subsection{Growth mechanism of spherulite}

Spherulites are formed in the crystallization process of many substances, which are especially characteristic of substances consisting large molecules, particularly, polymers. This characteristic feature of a spherulite is due to no coincidence of one of the crystallographic axes with the direction of the molecule chains lying along the radius of spherulite (Sheftal 1968).

Spherulite shapes may be explained perfectly satisfactorily via a model of a sheet of paper crumpled into folds, the edges being compressed toward the centre, giving the crystal a spherical shape (Sheftal 1968).

\section{Characterization}

\section{$4.1 X$-ray diffraction}

X-ray powder diffractograms were recorded using Minislex model, Rigaku ( $\mathrm{CuK} \alpha$ radiation, scanning speed, $10 \% \mathrm{~min}$ ). Figure 5 shows X-ray diffractogram of barium oxalate.

From the diffractograms, $d$-values for different $h k l$ were computed. The computer program, POWD (an Interactive Powder Diffraction Data Interpretation and Indexing Program, Version 2.2) was used to calculate ' $d$ ' values. Calculated ' $d$ ' values matched with reported values. Table 2 shows calculated unit cell parameters.

Table 2. Calculated unit cell parameters.

\begin{tabular}{lc}
\hline Parameters & Barium oxalate \\
\hline System & Monoclinic $(\mathrm{P})$ \\
$a$ & $8 \cdot 2426 \AA$ \\
$b$ & $4.0458 \AA$ \\
$c$ & $6 \cdot 4706 \AA$ \\
$\beta$ & $92 \cdot 319 \AA$ \\
$\mathrm{V}$ & $215.60 \AA^{3}$ \\
\hline
\end{tabular}

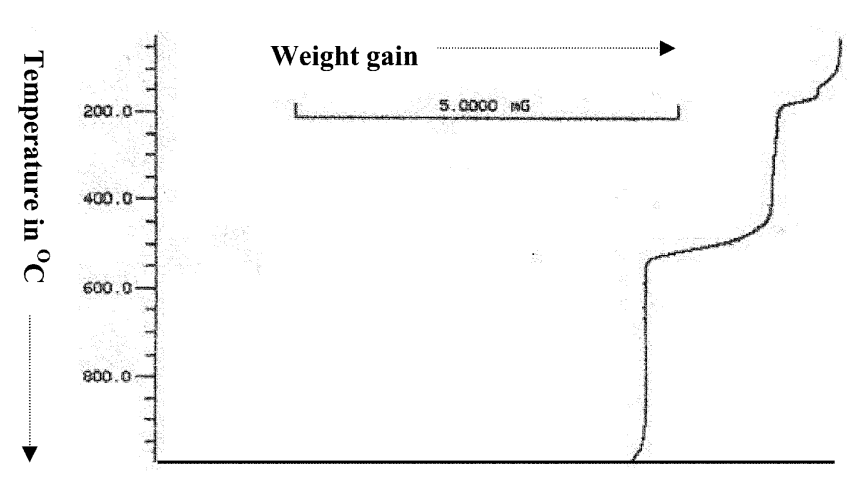

Figure 7. Thermogravimetric analysis (TGA) of barium oxalate.

\subsection{Infrared spectra}

IR absorption spectrum of barium oxalate crystals (figure 6) shows a well pronounced broad intense peak at $3556.72 \mathrm{~cm}^{-1}$, which is attributed to asymmetric and symmetric $\mathrm{O}-\mathrm{H}$ stretching and the peak at $1615.67 \mathrm{~cm}^{-1}$ is related to $\mathrm{O}-\mathrm{H}$ bending vibration, which established the presence of water of crystallization. The sharp peak at $782.84 \mathrm{~cm}^{-1}$ may be attributed to metal-oxygen bond.

\subsection{Thermal analysis}

TGA and DTA of grown crystals were carried out at the National Chemical Laboratory, Pune, by Mettler TA4000 system.

TGA curves (figure 7) show that the compound is stable up to $54^{\circ} \mathrm{C}$. It loses $2 \%$ in weight in the temperature range $54-142^{\circ} \mathrm{C}$ which may be due to loss of moisture. The $3.75 \%$ loss in weight may be due to dehydration of 0.5 water molecule in the temperature range $142 \cdot 7-217 \cdot 3^{\circ} \mathrm{C}$. There is no further weight loss up to $408.7^{\circ} \mathrm{C}$ and hence barium oxalate is completely dehydrated.

The $11.701 \%$ losses in weight, in the temperature range $408 \cdot 7-558^{\circ} \mathrm{C}$, suggest loss of $\mathrm{CO}$. The compound remains stable up to $992^{\circ} \mathrm{C}$, and then starts to decompose. It may be due to loss of $\mathrm{CO}_{2}$. This thermal behaviour in terms of scheme (Raju et al 1998) may be explained as below:

$$
\begin{aligned}
& \mathrm{BaC}_{2} \mathrm{O}_{4} 0 \cdot 5 \mathrm{H}_{2} \mathrm{O} \stackrel{142 \cdot 7-217 \cdot 3^{\circ} \mathrm{C}}{\longrightarrow} \mathrm{BaC}_{2} \mathrm{O}_{4}+0 \cdot 5 \mathrm{H}_{2} \mathrm{O}, \\
& \mathrm{BaC}_{2} \mathrm{O}_{4} \stackrel{408 \cdot 7-588^{\circ} \mathrm{C}}{\longrightarrow} \mathrm{BaCO}_{3}+\mathrm{CO} \\
& \mathrm{BaCO}_{3} \stackrel{992^{\circ} \mathrm{C}}{\longrightarrow} \mathrm{BaO}+\mathrm{CO}_{2} .
\end{aligned}
$$

The weight loss of the grown sample is further supported by DTA (figure 8) analysis at the respective temperatures.

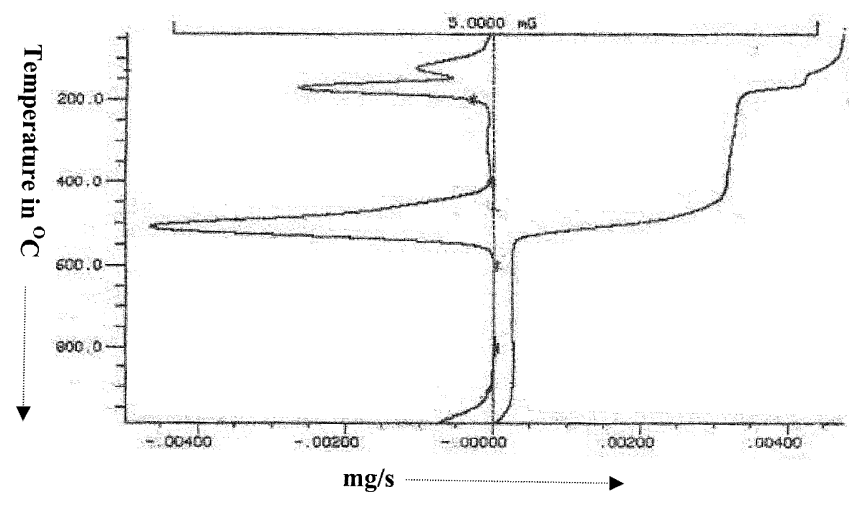

Figure 8. Thermal analysis (DTA/TGA) of barium oxalate. 


\section{Conclusions}

From the above studies we observe that:

(I) Gel growth technique is suitable for growing crystals of barium oxalate.

(II) Single and double diffusion methods show variation in the growth mechanisms.

(III) XRD results obtained, especially ' $d$ ' values, matched with the standard JCPDS data.

(IV) The study of characteristic peaks obtained (IR) reveals the presence of metal oxygen bond.

(V) Loss of 0.5 water molecule by dehydration around $142 \cdot 7-217 \cdot 3^{\circ} \mathrm{C}$ (endothermic), the evolution of $\mathrm{CO}$ around $408.7-558^{\circ} \mathrm{C}$ and $\mathrm{CO}_{2}$ around $992^{\circ} \mathrm{C}$ (exothermic) and yielding stable residual barium oxide beyond $992^{\circ} \mathrm{C}$ are seen.

\section{Acknowledgements}

The authors thank the Head, Department of Physics, Pratap College, Amalner, for providing laboratory facilities, Dr N R Shah, Department of Chemistry, Pratap College, Amalner, for fruitful discussion on IR and Prof. P P Patil, Director, North Maharashtra University, Jalgaon, for providing characterization facilities.

\section{References}

Agrawal B P, Chauhan K M and Bhadbhade M M 1999 Indian J. Pure \& Appl. Phys. 37395
Armington A F and O'Cornnar J J 1968 J. Cryst. Growth 3/4 367

Arora S K 1981 Prog. Crystal Growth Charact. 4345

Arora S K and Tony Abraham 1981 Indian J. Pure \& Appl. Phys. 19199

Bangera Kasthuri V and Mohan Rao P 1992 Bull. Mater. Sci. 15339

Barkley J R, Brixner L H and Hogan E M 1971 IEEE symposium on the application of ferroelectrics (New York: York Town Heights)

Barkley J R, Brixner L H, Hogan E M and Waring R K 1972 J. Ferroelectrics 3191

Brezina B and Harvankova M 1991 Mater. Res. Bull. 87537

Caillaud F, Baumard J F and Smith A 1988 Mater. Res. Bull. 23 1273

Dennis J and Henisch H K 1967 J. Electrochem. Soc.(USA) 114 263

Ittyachen M A and Kurien K V 1979 J. Cryst. Growth 47743

Jayakumari Isac, Raju K S and Ittyachen M A 1995 Bull. Mater. Sci. 19495

Joshi M S and Trivedi S G 1970 Kryst. Und Technol. 151131

Joshi M S, Mohan Rao P and Antoni A V 1981 Bull. Mater. Sci. 2127

Pactor A 1977 Krist. \& Technol. 12729

Prasad N V, Prasad G, Bhimasankaram T, Suryanarayana S V and Kumar G S 1996 Bull. Mater. Sci. 19639

Raju K S, Varughese John and Ittyachen M A 1998 Bull. Mater. Sci. 21375

Ranadive D, Blank Z, Brenner W and Okamoto Y 1969 Nature 223829

Sapriel J and Vacher R 1977 J. Appl. Phys. 481191

Sheftal N N 1968 Growth of crystals (New York: Consultants Bureau)

Sushma Bhat, Kotru P N and Raju K S 1995 Curr. Sci. 69607 